\title{
MELD—good for many, not as good for others ... at least for now
}

\author{
Thomas Schiano
}

Received: 26 November 2011 / Accepted: 5 July 2012/Published online: 25 July 2012

(C) Asian Pacific Association for the Study of the Liver 2012

Since its introduction in early 2002 as the prioritization system utilized by the United Network for Organ Sharing (UNOS) for patients on liver transplant waiting lists in the United States, the model for end stage liver disease (MELD) [1-3] has been extensively validated over time as a very sensitive predictor of pre-transplant mortality. Part of the success of the MELD system has been the foresight of UNOS to continuously reexamine MELD and be open to modifying it, so as to address inequities that might favor or prejudice certain patient groups. This is in fulfillment of the "final rule" of the organ procurement and transplantation network (OPTN) ensuring that all patients have as equal access to transplantation as possible [4]. For instance, in the early days of MELD, patients with small hepatocellular carcinoma (HCC) were given priority on the transplant waiting list ( $\mathrm{T} 1$ lesions) and patients meeting the current $\mathrm{T} 2$ criteria were given higher priority than they currently have. T1 listing was done away with and patients with T2 criteria were assigned lower MELD scores when analysis suggested that patients with HCC were being given too much priority on the list and that non-HCC patients might be suffering the consequences of less access to organs and higher death rates on the waiting list $[5,6]$. There are now specific disease states that allow patients to receive additional MELD priority scores, such as hepatopulmonary syndrome, portopulmonary hypertension, and familial amyloidosis [7]. Realization that patients with low MELD scores having hyponatremia are more likely to die on the waiting list has spurred ongoing research to assess whether an adjusted MELD score in this setting would be warranted [8]. Even patients having certain cholangiocarcinomas are

T. Schiano $(\bowtie)$

Mount Sinai School of Medicine, New York, NY, USA

e-mail: Thomas.Schiano@mountsinai.org now given priority in the waiting list because research has demonstrated appreciable survival with aggressive treatment protocols [9].

The success of MELD has captured the interest of the transplant community outside of the United States, and it has now been adopted by many other countries [10-13]. MELD has also been shown to have utility in predicting outcome in patients suffering from acute liver failure, alcoholic hepatitis, and in patients with chronic liver disease undergoing surgery or experiencing traumatic injury [14-18]. To date, however, it has not been shown to reliably predict post-liver transplant mortality. In listed patients with small changes in MELD score (delta MELD), there can be appreciable changes in pre-transplant mortality, although studies do not convincingly show this to be a strong predictor for having a bad outcome [19, 20].

In the issue of Hepatology International, Badr Al-Freah and colleagues [21] reviewed the results of an analysis of patients listed between 1998 and 2005 at the New Zealand Liver Transplant Unit with retrospective calculation of the MELD score at the time of listing and subsequently at the time of transplantation. They took into account prioritization points for HCC and studied 264 patients. Typically, patients in Australia and New Zealand are prioritized to transplantation when they are Child's Class $\mathrm{C}$ and have had complications of portal hypertension, with hospitalized patients being further prioritized. The investigators found that MELD scores at transplant as well as delta MELD scores did not correlate with 3- and 12-month post-transplant mortality. The authors concluded that the MELD allocation system would not be helpful in New Zealand, which has a single transplant center and organ procurement organization, and I am in agreement with this. Their results are not surprising in light of the fact that median waiting time prior to transplantation was 72 days and the MELD 
score at listing (unadjusted for HCC) was 15 with only $20 \%$ of patients having a MELD score $>20$. The program achieved an outstanding 1-year survival rate of $94 \%$. Patients were listed for HCC if they met University of California, San Francisco (UCSF) criteria [22] or Milan criteria [23] and were assigned 24 points instead of 22 . There was no real delta MELD, not unexpected since the waiting time was short. Of the total patients, $15 \%$ $(n=38)$ were delisted with $23.7 \%$ dying of sepsis/multiorgan failure and tumor progression in $14(36.8 \%)$. A $15 \%$ waiting list death rate seems somewhat high in light of the overall comparatively low MELD scores with which the patients were listed. Death from infection in decompensated cirrhotic patients is not unusual, however, and if one excluded the large number of patients dying from HCC progression, the number of patients dying on their waiting list was under $10 \%$.

Some data which the investigators did not provide and that which would have been helpful in further critically examining their results and trying to extrapolate them to the current MELD system of the United States are as follows: the specifics of the actual MELD score (i.e., how many patients had renal failure or were on hemodialysis); were patients with HCC actively being treated with locoregional therapy while on the list or did they initially have HCC fulfilling UCSF criteria and were then downstaged into fulfilling Milan criteria; what were the miscellaneous diagnoses for listing (28\% of the patients); and finally what were the causes of death of the patients dying during the first year after the transplant. No information is provided on the donor organs with regard to length of cold ischemia time and donor age, both of which can affect post-liver transplant outcome. The majority of organs presumably were procured locally and had short ischemic times, and the program could probably be more selective in matching recipient and donor. One-third of patients were listed for accepted MELD exceptions but the authors do not specify what the indications were and how many MELD points were allotted. Their patient population is very different from that seen in Europe and the United States with many more patients having hepatitis $\mathrm{B}$, their use of the UCSF criteria in an overall lower percentage of HCC patients being listed for transplant, and overall lower MELD scores and shorter waiting times for all listed patients. Thus, their results are not really applicable to the current transplant environment faced by the majority of liver transplant programs relying on deceased donor organs at a time of organ donor scarcity. Further, data on the comparative successes of the other programs in the Australasian system would also be of interest.

Despite these methodological shortcomings and comparative disparities in demographics, I believe that the results of Badr Al-Freah and colleagues are a clarion example of ideally how transplant prioritization and allocation of organs could work. The Australasian system is unit-based with donors obtained from their own procurement unit first offered to that particular transplant center and offered out only on a strict rotating basis when not accepted by that program. Their overall number of patients on liver transplant lists is small and patients are thus effectively managed by transplant physicians who have close relationships with their patients and knowledge of their medical histories, thus allowing the physicians to detect subtle changes in their patients' conditions. I am sure that these close relationships, which we all strive for but often are unable to achieve because of the sheer number of patients flooding United States and European transplant centers, translate into better patient satisfaction and posttransplant compliance.

Currently, in the United States, there are geographic disparities in liver allocation with some regions of the country being able to transplant livers in patients having MELD scores of 20 and some regions of the country being able to transplant livers in patients with MELD scores closer to 30. This is having a clear negative impact on waiting list mortality and post-liver transplant patient and graft survival in many centers, despite the innovative and skillful techniques of the liver transplant surgeons having to place more extended donor organs into sicker patients. Unfortunately, there may be no light at the end of the tunnel as the number of patients developing decompensated liver disease and HCC is expected to increase well into the future. Hopefully, calls for changing the current liver allocation in the United States will not fall on deaf ears and changes can be instituted that take advantage of a broader geographic donor sharing.

I agree with Badr Al-Freah and colleagues in that New Zealand currently does not require MELD to achieve excellent post-transplant survival of their patients. Their waiting list mortality would be just as outstanding as their post-transplant survival if patients were listed with Milan criteria staging of their HCC rather than UCSF criteria. However, as the number of patients increases on their waiting list and the need and demand for transplantation soars in New Zealand, the time-tested benefits of MELD will need to be reassessed.

\section{References}

1. Kamath PS, Wiesner RH, Malinchoc M, et al. A model to predict survival in patients with end-stage liver disease. Hepatology 2001;33:464-470

2. Bernardi M, Gitto S, Biselli M. The MELD score in patients awaiting liver transplant: strengths and weaknesses. J Hepatol 2011;54:1297-1306 
3. Bambha K, Kim WR, Kremers WK, et al. Predicting survival among patients listed for liver transplantation: an assessment of serial MELD measurements. Am J Transplant 2004;4:1798-1804

4. Brown RS Jr, Higgins R, Pruett TL. The evolution and direction of OPTN oversight of live organ donation and transplantation in the United States. Am J Transplant 2009;9:31-34

5. Wiesner RH, Freeman RB, Mulligan DC. Liver transplantation for hepatocellular cancer: the impact of the MELD allocation policy. Gastroenterology 2006;127:S261-S267

6. Sharma P, Harper AM, Hernandez JL, et al. Reduced priority MELD score for hepatocellular carcinoma does not adversely impact candidate survival awaiting liver transplantation. Am J Transplant 2006;6:1957-1962

7. Massie AB, Caffo B, Gentry SE, et al. MELD exceptions and rates of waiting list outcomes. Am J Transplant 2011;11(11): 2362-2371

8. Kim WR, Biggins SW, Kremers WK, et al. Hyponatremia and mortality among patients on the liver-transplant waiting list. N Engl J Med 2008;359:1018-1026

9. Rosen CB, Heimbach JK, Gores GJ. Liver transplantation for cholangiocarcinoma. Transpl Int 2010;23:692-697

10. Jacob M, Copley LP, Lewsey JD, et al. Pretransplant MELD score and post liver transplantation survival in the UK and Ireland. Liver Transpl 2004;10:903-907

11. Tenório AL, Macedo FI, Miranda LE, et al. Survival on waiting list for liver transplantation before and after introduction of the model for end-stage liver disease score. Transplant Proc 2010;42:407-411

12. Foxton MR, Al-Freah MA, Portal AJ, et al. Increased model for end-stage liver disease score at the time of liver transplant results in prolonged hospitalization and overall intensive care unit costs. Liver Transpl 2010;16:668-677

13. McCormack L, Gadano A, Lendoire J, et al. Model for end-stage liver disease-based allocation system for liver transplantation in
Argentina: does it work outside the United States? HPB (Oxford) 2010;12:456-464

14. Westbrook RH, Yeoman AD, O'Grady JG, et al. Model for endstage liver disease score predicts outcome in cirrhotic patients during pregnancy. Clin Gastroenterol Hepatol 2011;9:694-699

15. Inaba K, Barmparas $\mathrm{G}$, Resnick $\mathrm{S}$, et al. The model for end-stage liver disease score: an independent prognostic factor of mortality in injured cirrhotic patients. Arch Surg 2011;146:1074-1078

16. Cho HC, Jung HY, Sinn DH, et al. Mortality after surgery in patients with liver cirrhosis: comparison of Child-Turcotte-Pugh, MELD and MELDNa score. Eur J Gastroenterol Hepatol 2011;23:51-59

17. Yantorno SE, Kremers WK, Ruf AE, et al. MELD is superior to King's college and Clichy's criteria to assess prognosis in fulminant hepatic failure. Liver Transpl 2007;13:822-828

18. Srikureja W, Kyulo NL, Runyon BA, et al. MELD score is a better prognostic model than Child-Turcotte-Pugh score or discriminant function score in patients with alcoholic hepatitis. J Hepatol 2005;42:700-706

19. Kim JD, Choi JY, Kwon JH, et al. Performance of posttransplant model for end-stage liver disease (MELD) and delta-MELD scores on short-term outcome after living donor liver transplantation. Transplant Proc 2009;41:3766-3768

20. Northup PG, Berg CL. Preoperative delta-MELD score does not independently predict mortality after liver transplantation. Am J Transplant 2004;4:1643-1649

21. Al-Freah MAB, et al. The effect of changes of model for endstage liver disease score during waiting time on post-liver transplant mortality. Hepatol Int 2012;6:491-497

22. Yao FY. Liver transplantation for hepatocellular carcinoma: beyond the Milan criteria. Am J Transplant 2008;8:1982-1989

23. Pomfret EA, Washburn K, Wald C, et al. Report of a national conference on liver allocation in patients with hepatocellular carcinoma in the United States. Liver Transpl 2010;16:262-278 